\title{
UNCERTAINTY IN THE THERMAL CONDUCTIVITY OF INSULATION MATERIALS
}

\author{
F. Domínguez-Muñoz ${ }^{1}$, B.Anderson ${ }^{2}$, J.M. Cejudo-López ${ }^{1}$, A. Carrillo-Andrés ${ }^{1}$ \\ ${ }^{1}$ Dpto. de Máquinas y Motores Térmicos, Grupo de Energética, Universidad de Málaga \\ Plaza El Ejido s/n, 29013 Málaga (Spain), e-mail:fdominguezm@uma.es \\ ${ }^{2}$ BRE Scotland. Orion House, Scottish Enterprise Technology Park, East Kilbridge, Glasgow \\ G75 0RD (Scotland, UK)
}

\begin{abstract}
Increasing attention is being paid to the application of uncertainty and sensitivity analysis methods to model validation and building simulation. The idea is to let users to apply uncertainty bands to their model input data. These bands are then propagated through the model to determine the uncertainty bands of the simulation results. Mathematical methods to deal with uncertainties in computer simulations are well developed. One of the main difficulties the practitioner finds when trying to apply these techniques to building simulation is the lack of information on the uncertainty that affects to typical input variables (thermophysical properties of materials, internal gains, infiltration, etc.). This paper is a contribution to fill this gap. We present polynomial fits for the average thermal conductivity and its standard deviation as functions of density for typical insulation materials. These functions were obtained by processing a large experimental data set, which was compiled in a previous European project headed by the BRE Scottish Laboratory. To illustrate how these results can be used in practice, an example is discussed on the validation of the mathematical model of a solar thermal collector.
\end{abstract}

\section{INTRODUCTION}

Insulation materials are extensively used to reduce the heat losses (or gains) from thermal systems like buildings, pipes and ducts, components of HVAC installations, etc. In these systems, the insulation layers account for most of the thermal resistance between the hot (or cold) element/s and the environment. Most mass-type thermal insulation materials are highly porous, and consist of a solid matrix full of small voids that comprise $90 \%$ or more of the total volume. These voids contain air or some other harmless gas such as $\mathrm{CO}_{2}$. The apparent conductivity of the material is the macroscopic result of various basic heat transfer mechanisms: solid and gas conduction, gas convection and long-wave radiation within the voids. From the macroscopic point of view, the apparent conductivity mainly depends on the kind of insulation, bulk density, temperature, water content, thickness and age. From the microscopic point of view, factors such as cell size, diameter and arrangement of fibres or particles, transparency to thermal radiation or type and pressure of the gas come into play (ASHRAE, 2005).

For a given aged material sample, the average conductivity mainly depends on density $(\rho)$, temperature $(T)$ and water content ( $w$, when the material is hygroscopic). However, these three factors do not fully explain the value of conductivity, and dispersion remains due to differences in raw material properties, manufacturing process, etc. Conductivity can then be written as an average value $(\bar{k})$ plus a random deviation $(\delta)$ :

$$
k=f(\rho, T, w \text {; other factors })=\bar{k}(\rho, T, w)+\delta
$$

For example, figure 1 shows a set of 1340 measurements for the conductivity of expanded polystyrene (EPS) at $10^{\circ} \mathrm{C}$, and dry and aged material. The key independent variable is density. Dispersion around the average conductivity is clearly seen in this figure.

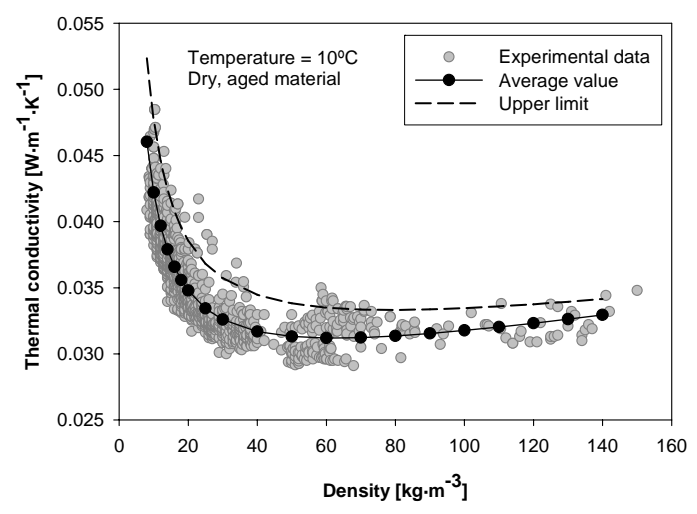

Figure 1 Measurements for EPS

Standard methods like the calibrated hotbox or the guarded hotbox (EN 12939, 2001) are the best procedures to determine the exact conductivity of a specific material sample. However, practical constrains often lead to use tabulated values. Wellknown and widely used sources of thermo-physical properties are (ASHRAE, 2005), (CIBSE, 2006), (EN12524, 2000), (ISO10456, 2001) and (EN1745, 2002). These references always provide design ("worst-case" or "safe”) values. In figure 1, this idea would correspond to the "upper limit" dashed curve, which normally stands for the $90 \%$ fractile. 
While design values are adequate for the majority of the simulation works, there are at least two situations in which practitioners need full information on how the conductivity spreads around the average: (a) validation studies, (b) building simulation under uncertainty. In both cases, inputs to the model are often described as probability distributions, and Monte Carlo simulations are performed to propagate these uncertainties to the result/s. Three examples of validation papers that require data on dispersion are (Strachan, 1993), (Palomo et al., 2003) and (Dominguez et al., 2008). Building simulation under uncertainty is a relatively new branch of building physics. Some of the pioneer works were (Lomas et al., 1992), (MacDonald, 2001) and (deWit, 2001).

In this paper, we provide explicit expressions for the average conductivity and its standard deviation for common insulation materials. To accomplish this task, the first problem we faced was to find enough quality-controlled measurements of conductivity for different densities and materials. Section 1 reviews the available data sources and describes the data set that has been used in this paper. Section 2 describes the fitting method applied on the raw measurements to derive the polynomial fitting equations. Section 3 presents the main results of the paper, the fitting coefficients. Section 4 is devoted to a case study that shows how the results of Section 3 can be used to validate the model of a thermal flat-plate solar collector. Section 5 presents the general conclusions and discusses further lines of research.

\section{DATA SOURCES}

Standard sources of thermo-physical properties have limitations that make it difficult to extract average values and standard deviations. To quantify the intrinsic uncertainty in the thermal conductivity of a material, a large and representative number of measurements is needed. In this section, we describe two data sources that are well suited for such a purpose.

The report (Clarke et al., 1990) has been the most extensive and best-known compilation of thermophysical properties of building materials for many years. It contains data from 14 international sources. This information was used in (MacDonald, 2001) to propose uncertainties for different material classes. However, the authors of the report identified some issues that limit the applicability of the data set that they provide:

- The sources of much of the data are not identified, and little information is given on the underlying experimental conditions or procedure, and on properties such as density and internal structure

- Much of the agreement that does exist between different sources may be attributable to historical 'borrowing' one from the other. This may lead to an optimistic assessment of the inherent uncertainty.

The “Thermal Values Group” (Anderson et al., 1999) collected a more comprehensive set of measurements in preparation of a new generation of European Standards on thermal properties; see, for example (EN 12524, 2000), (ISO 10456, 2001) and (EN1745, 2002). This working group consisted of seven national European laboratories that compiled hundreds of measurements of conductivity of different materials. Samples from several European manufactures were tested.

This paper is based on the measurements collected by the Thermal Values Group for insulation materials. The format of the available data will now be briefly described. As conductivity depends on temperature, water content and age, all measurements were referenced to standard conditions, in particular to "declared conditions I(a)" as defined in (ISO 10456, 2001): average temperature $10^{\circ} \mathrm{C}$, dry and aged material. The raw data has the following format:

$$
\left[\rho, k\left(10^{\circ} C, d r y, \text { aged }\right)\right]_{n \text { pairs }}
$$

where $n$ is the number of available data points and $\rho$ is the bulk density. Table 1 lists the materials considered in this paper and the number of measurements available for each of them.

Table 1

Available data

\begin{tabular}{|c|l|c|}
\hline & \multicolumn{1}{|c|}{ Material } & $\boldsymbol{n}$ \\
\hline $\mathbf{1}$ & Expanded polystyrene (EPS) & 3873 \\
\hline $\mathbf{2}$ & Extruded polystyrene (XPS) $\mathrm{CO}_{2}$ & 122 \\
\hline $\mathbf{3}$ & Polyurethane with pentane & 148 \\
\hline $\mathbf{4}$ & Foil-faced polyurethane pentane & 111 \\
\hline $\mathbf{5}$ & Polyurethane with $\mathrm{CO}_{2}$ & 14 \\
\hline $\mathbf{6}$ & Polyester fibre & 16 \\
\hline $\mathbf{7}$ & Phenolic foam & 19 \\
\hline $\mathbf{8}$ & Mineral wool (rock), flow $\perp$ fibre & 1657 \\
\hline $\mathbf{9}$ & Mineral wool (glass) & 1340 \\
\hline $\mathbf{1 0}$ & Cellular glass / foam glass & 120 \\
\hline $\mathbf{1 1}$ & Wood chip board & 13 \\
\hline $\mathbf{1 2}$ & Wood fibre board & 81 \\
\hline $\mathbf{1 3}$ & Wood wool board & 161 \\
\hline $\mathbf{1 4}$ & Sheep’s wool & 97 \\
\hline $\mathbf{1 5}$ & Cotton & 20 \\
\hline $\mathbf{1 6}$ & Expanded cork & 78 \\
\hline $\mathbf{1 7}$ & Expanded perlite board & 51 \\
\hline $\mathbf{1 8}$ & Cellulose fibre (loose-fill) & 282 \\
\hline
\end{tabular}

\section{METHODOLOGY}

In (Anderson et al., 1999), data set (2) was processed to calculate the $50 \%$ and $90 \%$ fractiles of the conductivity of each material at different densities. The $90 \%$ fractiles are commonly used in heat transfer calculations. For example, they are used in the new 
Spanish energy standard and in its calculation tool (CTE, 2007).

In the present paper, data set (2) was processed to fit equations for the average conductivity and its standard deviation (uncertainty band):

$$
\begin{aligned}
\bar{k} & =f\left(\rho ; T=10^{\circ} C, w \simeq 0, \text { aged }\right) \\
\sigma & =g\left(\rho ; T=10^{\circ} C, w \simeq 0, \text { aged }\right)
\end{aligned}
$$

Assuming a normally distributed deviation, the true value of the conductivity of any sample would lie within the interval [ $\bar{k} \pm 2 \sigma$ ] with a $95.5 \%$ probability, and within $[\bar{k} \pm 3 \sigma]$ with a $99.7 \%$ probability.

After testing several regression models, materials in table 1 were divided into two categories. The first group comprises materials 2, 3, 4, 5 and 7. These materials do not show a clear dependency between conductivity and density within the considered density range, so functions $f$ in (3) and $g$ in (4) reduce to constant values. For the rest of materials, the following simple regression model fits well the averages:

$$
\bar{k}=a+b \rho+c \rho^{-1}
$$

Parameters $a, b$ and $c$ are usually estimated by the ordinary least squares method OLSQ, see (Press, 1992). This method assumes a constant standard deviation, so equation (4) reduces to:

$$
\sigma=d=\text { constant }
$$

However, a close examination of the residuals of the regression models shows that materials $1,9,15$ and 18 exhibit a significant relationship between the standard deviation of conductivity ( $\sigma$, dependent variable) and density ( $\rho$, independent variable). This property of the data is called heteroscedasticity. In these cases, standard deviation was fitted by another polynomial function:

$$
\sigma=d+e \rho+f \rho^{-1}
$$

Coefficients in equations (5) and (7) were estimated by the weighted least squares method WLSQ, see (NIST, 2006) and (STATSOFT, 2009).

Figure 2 is an example on how the WLSQ method improves the results when compared to the OLSQ method. WLSQ-calculated uncertainty bands (dashed lines in figure 2) more closely resemble the measured data, whose deviation decreases with density.

\section{$\underline{\text { RESULTS }}$}

Table 2 shows the coefficients of the polynomials (5) and (7) for those materials whose conductivity changes with density. Table 3 shows maximum, minimum, standard deviation and two extreme fractiles (1\% and 99\%) for the rest of materials in table 1.
It is important to remark that tables 2 and 3 give the conductivity at declared conditions I(a). Conversion from declared conditions to another set of conditions can be carried out accordingly to the method explained in (ISO 10456, 1999).

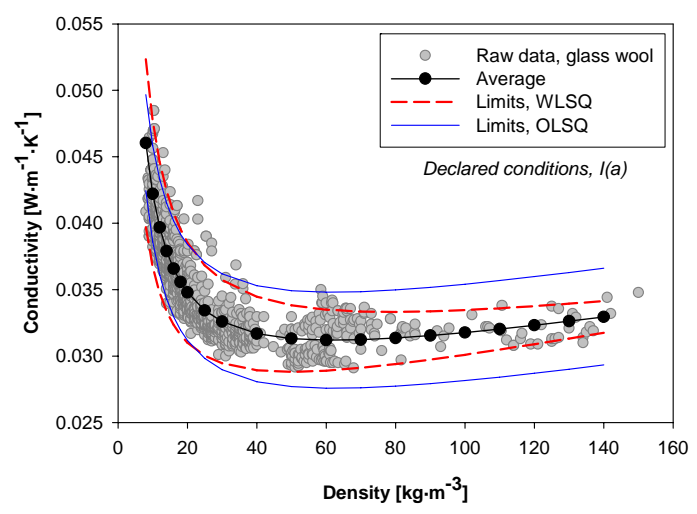

Figure 2 Weighted vs. ordinary least squares fit

\section{CASE STUDY}

This case study illustrates how data from table 2 can be used in a model validation exercise. The aim is to validate the well known Hottel-Whillier flat plate solar collector model; see (Duffie et al., 2006) and (Koo, 1999) for details.

Figure 3 depicts the basic elements of a sheet-andtube solar collector. The following discussion will focus on the back insulation layer. The complete validation study can be found in (Dominguez et al., 2008).

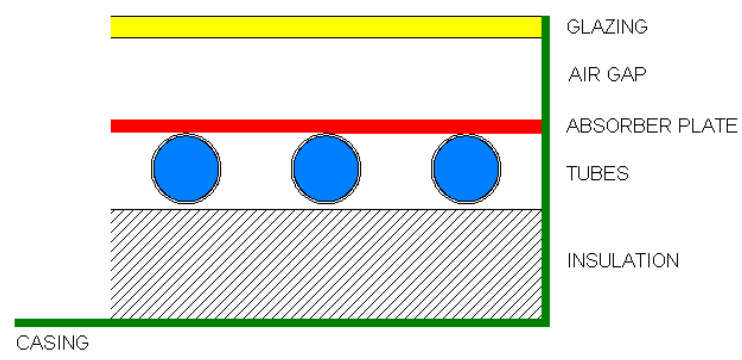

Figure 3 Section of a flat plate solar collector

In this kind of solar collector, an absorber plate with high solar absorptance and low emittance absorbs solar radiation and transfers the energy to a working fluid flowing through the tubes. In order to reduce the heat losses from the plate to the ambient, the plate is put into a weatherproof casing with one or two frontal glass covers and insulation behind and around the plate. Insulation normally consists of a layer of fibreglass, mineral fibre or polyester fibre.

The mathematical model of the collector requires around 20 input parameters to determine the efficiency curve. One of these parameters is the conductivity of the back insulation, in this case a mineral fibre mat $55 \mathrm{~cm}$. thick, with nominal density $70 \mathrm{~kg} / \mathrm{m}^{3}$. From table 2, the conductivity of this material at $10^{\circ} \mathrm{C}$ is: 
Table 2

Coefficients $a, b, c, d, e, h$ for materials whose conductivity depends on density, and minimum and maximum density of available data (declared conditions I(a)). Results in $\mathrm{W} / \mathrm{m} \cdot \mathrm{K}$

\begin{tabular}{|c|c|c|c|c|c|c|}
\hline \multirow{2}{*}{\multicolumn{3}{|c|}{ Material }} & $a$ & $b$ & $\boldsymbol{c}$ & \multirow{2}{*}{$\begin{array}{l}\text { Density range } \\
\mathrm{kg} / \mathrm{m}^{3}\end{array}$} \\
\hline & & & \multirow{2}{*}{$\frac{d}{2.49384 \mathrm{e}-2}$} & \multirow{2}{*}{$\frac{\boldsymbol{e}}{6.02766 \mathrm{e}-5}$} & \multirow{2}{*}{$\frac{\boldsymbol{f}}{1.77148 \mathrm{e}-1}$} & \\
\hline \multirow{2}{*}{1} & \multirow{2}{*}{ Expanded polystyrene EPS } & $\mu$ & & & & \multirow{2}{*}{$8-58.7$} \\
\hline & & $\sigma$ & $9.80350 \mathrm{e}-4$ & $-7.67465 e-6$ & $9.24900 \mathrm{e}-3$ & \\
\hline \multirow{2}{*}{6} & \multirow{2}{*}{ Polyester fibre } & $\mu$ & $2.45065 \mathrm{e}-2$ & $6.71341 \mathrm{e}-5$ & $2.20565 \mathrm{e}-1$ & \multirow{2}{*}{$11.2-44.6$} \\
\hline & & $\sigma$ & $2.30170 \mathrm{e}-3$ & 0 & 0 & \\
\hline \multirow{2}{*}{8} & \multirow{2}{*}{$\begin{array}{l}\text { Mineral wool (rock), } \\
\text { flow } \perp \text { fibre }\end{array}$} & $\mu$ & $2.61054 \mathrm{e}-2$ & 5.57568e-5 & $2.49860 \mathrm{e}-1$ & \multirow{2}{*}{$13.3-241$} \\
\hline & & $\sigma$ & $1.56918 \mathrm{e}-3$ & 0 & 0 & \\
\hline \multirow{2}{*}{9} & \multirow{2}{*}{ Mineral wool (glass) } & $\mu$ & $2.61624 \mathrm{e}-2$ & $4.04561 \mathrm{e}-5$ & $1.56332 \mathrm{e}-1$ & \multirow{2}{*}{$8-150$} \\
\hline & & $\sigma$ & $1.02890 \mathrm{e}-3$ & $-4.33900 \mathrm{e}-6$ & $1.41980 \mathrm{e}-2$ & \\
\hline \multirow{2}{*}{10} & \multirow{2}{*}{ Cellular glass / foam glass } & $\mu$ & $1.85584 \mathrm{e}-2$ & $1.87513 \mathrm{e}-4$ & 0 & \multirow{2}{*}{$100-188$} \\
\hline & & $\sigma$ & $1.71036 \mathrm{e}-3$ & 0 & 0 & \\
\hline \multirow{2}{*}{11} & \multirow{2}{*}{ Wood chip board } & $\mu$ & $1.48614 \mathrm{e}-2$ & $1.39123 \mathrm{e}-4$ & 0 & \multirow{2}{*}{$309-681$} \\
\hline & & $\sigma$ & $6.56175 \mathrm{e}-3$ & 0 & 0 & \\
\hline \multirow{2}{*}{12} & \multirow{2}{*}{ Wood fibre board } & $\mu$ & $3.03256 \mathrm{e}-2$ & $7.00099 \mathrm{e}-5$ & 0 & \multirow{2}{*}{$100-298$} \\
\hline & & $\sigma$ & $1.54876 \mathrm{e}-3$ & 0 & 0 & \\
\hline \multirow{2}{*}{13} & \multirow{2}{*}{ Wood wool board } & $\mu$ & $1.89255 \mathrm{e}-2$ & $1.26715 \mathrm{e}-4$ & 0 & \multirow{2}{*}{$260-719$} \\
\hline & & $\sigma$ & $6.92648 \mathrm{e}-3$ & 0 & 0 & \\
\hline \multirow{2}{*}{14} & \multirow{2}{*}{ Sheep’s wool } & $\mu$ & $2.82549 \mathrm{e}-2$ & 3.31991e-6 & 2.16252E-1 & \multirow{2}{*}{$11-93.2$} \\
\hline & & $\sigma$ & $1.57101 \mathrm{e}-3$ & 0 & 0 & \\
\hline 15 & Cotton & $\mu$ & $2.88085 \mathrm{e}-2$ & $6.55360 \mathrm{e}-5$ & 1.23810E-1 & $11-60$ \\
\hline 15 & (6) & $\sigma$ & $6.87650 \mathrm{e}-4$ & $1.54486 \mathrm{e}-5$ & $1.02140 \mathrm{e}-2$ & $11-00$ \\
\hline 16 & Eynanded cork & $\mu$ & 3.43283e-2 & $5.21174 \mathrm{e}-5$ & 0 & \\
\hline 10 & 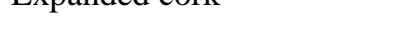 & $\sigma$ & $1.49955 \mathrm{e}-3$ & 0 & 0 & r \\
\hline 17 & Fxnanded nerlite hoard & $\mu$ & $4.43894 \mathrm{e}-2$ & $3.21588 \mathrm{e}-5$ & 0 & 134 \\
\hline & & $\sigma$ & $1.12308 \mathrm{e}-3$ & 0 & 0 & \\
\hline 18 & Collulose fihre (lonse_fill) & $\mu$ & $2.63462 \mathrm{e}-2$ & $1.36113 \mathrm{e}-4$ & 2.08963e-1 & $17-115$ \\
\hline 10 & 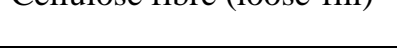 & $\sigma$ & $1.03085 \mathrm{e}-3$ & $1.87000 \mathrm{e}-6$ & $2.38950 \mathrm{e}-3$ & 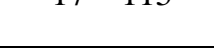 \\
\hline
\end{tabular}

Table 3

Declared conductivity and density range for materials whose conductivity does not depend on density

\begin{tabular}{|c|c|c|c|c|c|c|c|c|}
\hline \multirow{2}{*}{\multicolumn{2}{|c|}{ Material }} & \multicolumn{6}{|c|}{ Declared conductivity $10^{\circ} \mathrm{C}$, dry $[\mathrm{W} / \mathrm{m} \cdot \mathrm{K}]$} & \multirow{2}{*}{$\begin{array}{c}\text { Density } \\
\text { range } \\
\mathrm{kg} / \mathrm{m}^{3}\end{array}$} \\
\hline & & & Standard & & & Fractile & Fractile & \\
\hline 2 & $\begin{array}{l}\text { Extruded polystyrene } \\
\text { (XPS) } \mathrm{CO}_{2}\end{array}$ & 0.034 & 0.0015 & 0.0317 & 0.0383 & 0.0317 & 0.0381 & $\begin{array}{c}31.0- \\
50.8 \\
\end{array}$ \\
\hline 3 & $\begin{array}{l}\text { Polyurethane with } \\
\text { pentane }\end{array}$ & 0.0295 & 0.0013 & 0.0250 & 0.0340 & 0.0263 & 0.0335 & $\begin{array}{c}28.8- \\
49.2\end{array}$ \\
\hline 4 & $\begin{array}{l}\text { Foil-faced polyurethane } \\
\text { pentane }\end{array}$ & 0.0246 & 0.0012 & 0.0211 & 0.0295 & 0.0227 & 0.0282 & $\begin{array}{c}28.9- \\
40 \\
\end{array}$ \\
\hline 5 & Polyurethane with $\mathrm{CO}_{2}$ & 0.0291 & 0.0042 & 0.0206 & 0.0349 & 0.0211 & 0.0348 & $\begin{array}{c}27.2- \\
114\end{array}$ \\
\hline 7 & Phenolic foam & 0.0287 & 0.0025 & 0.0241 & 0.0307 & 0.0241 & 0.0307 & $\begin{array}{c}19.2- \\
45\end{array}$ \\
\hline
\end{tabular}


$\bar{k}_{10, d r y}=0.0261054+5.57568 \cdot 10^{-5} \cdot 70+0.24986 / 70=$

$=0.0336\left[\mathrm{~W} \cdot \mathrm{m}^{-1} \cdot \mathrm{K}^{-1}\right]$

$\sigma=0.001569\left[\mathrm{~W} \cdot \mathrm{m}^{-1} \cdot \mathrm{K}^{-1}\right]$

This means that the declared conductivity of the back insulation can be modelled by the following normal probability distribution:

$$
k_{10^{\circ} \mathrm{C}, d r y}=N[0.0336,0.001569] \mathrm{W} / \mathrm{m} \cdot \mathrm{K}
$$

Equation (8) tells us that, although the exact value of the declared conductivity of the back insulation of the tested collector is unknown, we can ensure that it will lie within [0.0289, 0.0383] $\mathrm{W} / \mathrm{m} \cdot \mathrm{K}$ with a $99.7 \%$ probability.

The operating temperature of the plate varies in a wide range, from near ambient temperature during nightime to more that $100^{\circ} \mathrm{C}$ during stagnation periods. Because of this reason, the temperaturedependency of the thermal conductivity was included in the model. Accordingly to (ISO 10456, 1999), conductivity can be converted from a reference temperature $\left(T_{r e f}\right)$ to any other temperature $(T)$ by using this expression:

$$
k(T)=k\left(T_{r e f}\right) \cdot \exp \left(f_{T}\left(T-T_{r e f}\right)\right)
$$

where $f_{T}$ is the temperature conversion factor, whose value depends on the kind of insulation and its declared conductivity. From data in table A.1 of (ISO 10456, 1999), $f_{T}$ will be approached by the following normal distribution:

$$
f_{T}=N[0.0042,0.000392] \mathrm{K}^{-1}
$$

Because the Hottel-Whillier model is onedimensional, the temperature at the upper face of the back insulation layer will be set to the average temperature of the absorber plate $\left(T_{m p}\right)$. Ambient temperature $\left(T_{a m b}\right)$ will be imposed at the bottom face of the insulation, figure 4.

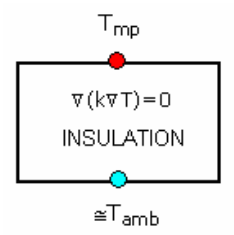

Figure 4 Insulation thermal model

The steady temperature field in the insulation layer is given by the Fourier law:

$$
\nabla(k \nabla T)=0
$$

subject to the following boundary conditions:

$$
\begin{gathered}
T(x=0)=T_{m p} \\
T\left(x=t_{\text {insul }}\right)=T_{a m b}
\end{gathered}
$$

Where $t_{\text {insul }}$ is the thickness of the insulation layer. The problem defined by equations (9) and (11) to (13) has the following analytical solution

$$
T(x)=T_{\text {ref }}+\frac{1}{f_{T}} \ln (\alpha x+\beta)
$$

where

$$
\begin{aligned}
& \alpha=\frac{\xi f_{T}}{k_{r e f}}, \quad \beta=\exp \left(f_{T}\left(T_{m p}-T_{r e f}\right)\right), \\
& \xi=\frac{k_{r e f}}{f_{T} t_{\text {insul }}} \exp \left(\frac{T_{a m b}-T_{r e f}}{T_{m p}-T_{r e f}}\right)
\end{aligned}
$$

In equation (9), $T$ stands for the average temperature of the material. Integrating equation (14):

$$
\begin{aligned}
& \bar{T}_{\text {insul }}=\frac{1}{t_{\text {insul }}} \int_{0}^{t_{\text {issul }}} T(x) d x= \\
& T_{\text {ref }}+\frac{1}{f_{T} t_{\text {insul }}}\left(\frac{\left(\alpha t_{\text {insul }}+\beta\right) \cdot \ln \left(\alpha t_{\text {insul }}+\beta\right)}{\alpha}-\frac{\beta \cdot \ln (\beta)}{\alpha}-t_{\text {insul }}\right)
\end{aligned}
$$

Finally, equation (9) can be written as:

$$
\begin{aligned}
& k(T)=N[0.00336,0.001569] . \\
& \exp \left(N[0.0042,0.000392]\left(\bar{T}_{\text {insul }}-10\right)\right)
\end{aligned}
$$

Where $\bar{T}_{\text {insul }}$ is calculated with equation (16). Other variables such us the transmittance of the glass cover, transport coefficients or plate emittance are treated in a similar way. All these uncertainties can be propagated through the model by applying the Monte Carlo method. A typical result is shown in figure 5 (Dominguez et al., 2008).

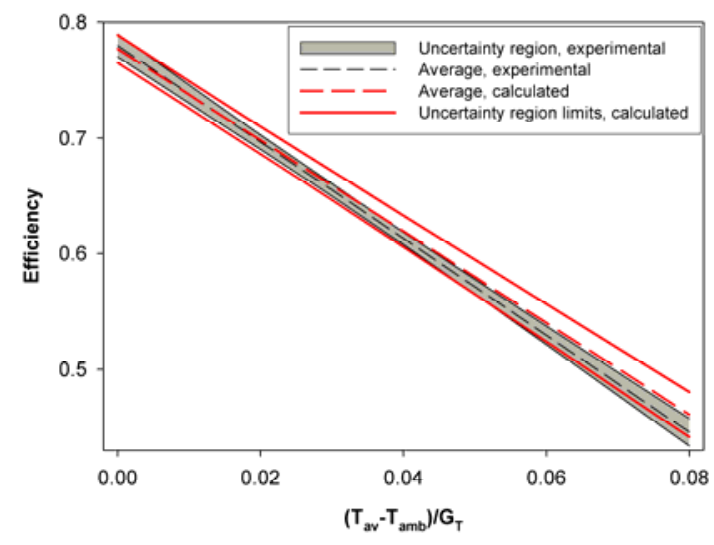

Figure 5 Measured and calculated efficiency curves with uncertainty bands

Model and experiment compare reasonably well, although the model under predicts the heat losses (slope of the curves shown in figure 5) by $5.75 \%$ on average. A sensitivity analysis (Saltelli et al., 2004) identifies what input factors dominate the uncertainty in the heat losses. The slope mainly depends on:

1. Insulation conductivity

2. Plate emittance

3. Natural convection in the air-gap

4. Temperature conversion factor $f_{T}$ 
5. Wind speed.

Four of these factors concern to input factors, not to the model itself. The differences between model and experiment could be explained if the true values of conductivity and/or plate emittance were slightly higher, and/or if their probability distributions were non-symmetrical. These results are helpful in pointing out future experimental research.

\section{CONCLUSION}

The lack of information on the uncertainty in input factors is one of the most important difficulties that users find when trying to undertake a stochastic simulation. In this paper, we provide results that give a general estimation of the uncertainty that affects to the thermal conductivity of 18 common insulation materials. Reported uncertainties were extracted from an extensive data set that comprise products from different European manufacturers. Reported uncertainties could be further reduced by analyzing products from specific manufacturers.

More research is encouraged to quantify the variability of the input data required by thermal systems simulation programs.

\section{REFERENCES}

AHSRAE, 2005. Fundamentals Handbook 2005

Anderson B.R., Kosmina L., Panzhauser E., Lechleitner J., Achtziger J., Sandberg P.I., Johnsson B., Pompeo C., Frank T., Mühlebach H., Torroja B., 1999. Analysis, selection and statistical treatment of thermal properties of building materials for the preparation of harmonised design values - Final Report of the Thermal Values Group. BRE Scottish Laboratory, for Directorate General DG XII of the European Commission, Contract SMT4CT96-2050, March 1999

CIBSE, 2006. Environmental design, CIBSE Guide A. The Chartered Institution of Building Services Engineers, London. ISBN: 978-1903287-66-8

Clarke J.A., Yaneske P.P., Pinney A.A., 1990. The Harmonisation of Thermal Properties of Building Materials. Building Research Establishment (BRE), available at $<w w w . e s r u . s t r a t h . a c . u k>$ access February 2009

CTE, 2007. Código Técnico de la Edificación, available at $\langle w w w$.codigotecnico.org $>$, access February 2009 (in Spanish)

De Wit M.S. 2001. Uncertainty in Predictions of Thermal Comfort in Buildings. Ph.D. Thesis, University of Delft, 2001

Domínguez-Muñoz F., Cejudo-López J.M., CarrilloAndrés A., 2008. Validación experimental del modelo de Hottel-Whillier de captador plano de tubos paralelos. XIV Congreso Ibérico y IX Congreso Iberoamericano de Energía Solar. Vigo, España. June 2008. ISBN 978-84-6124470-6 (in Spanish)

Duffie J.A., Beckman W.A., 2006. Solar Engineering of Thermal Processes. Third Edition, John Wiley and Sons. ISBN 978-0-471-69867-8

EN 12524, 2000. Building Materials and Products Hygrothermal Properties - Tabulated Design Values

EN 12939, 2001. Thermal performance of building materials and products - Determination of thermal resistance by means of guarded hot plate and heat flow meter methods - Thick products of high and medium thermal resistance

EN 1745, 2002. Masonry and masonry products. Methods for determining design thermal values

ISO 10456, 2001. Building materials and products Procedures for determining declared and design thermal values

Koo J., 1999. Development of a flat-plate solar collector design program. Master Thesis, Solar Energy Laboratory (SEL), University of Wisconsin-Madison, 1999

Lomas K.J., Eppel H., 1992. Sensitivity analysis techniques for building thermal simulation programs. Energy and Buildings, 19(1992) 2144

MacDonald I.A., 2001. Quantifying the effects of uncertainty in building simulation. Ph.D. Thesis, University of Strathclyde, July 2002

NIST 2006, NIST/SEMATECH e-Handbook of Statistical Methods, see (access February 2009) <http://www.itl.nist.gov/div898/handbook>

Palomo del Barrio E., Guyon G., 2003. Using parameters space analysis techniques for diagnostic purposes in the framework of empirical model validation - Theory, applications and computer implementation. A Report of Task 22, Subtask A. Building Energy Analysis Tools. IEA, International Energy Agency, Solar Heating and Cooling Programme

Press W.H. et al., 1992. Numerical Recipes in Fortran 77, volume 1. Cambridge University Press

Saltelli A., Tarantola S., Campolongo F., Ratto M., 2004. Sensitivity analysis in practice. John Wiley \& Sons. ISBN 0-470-87093-1

STATSOFT,2008. Statgraphics software.

Strachan P., 1993. Model Validation using the PASSYS Test Cells. Building and Environment, Vol. 28, No. 2, pp. t53-165 